\title{
RELATIONSHIPS AMONG SPECIES TRAITS: SEPARATING LEVELS OF RESPONSE AND IDENTIFYING LINKAGES TO ABUNDANCE
}

\author{
Katharine Nash Suding, ${ }^{1}$ Deborah E. Goldberg, and Kurt M. Hartman ${ }^{2}$ \\ Department of Ecology and Evolutionary Biology, University of Michigan, Ann Arbor, Michigan 48109-1048 USA
}

\begin{abstract}
We test the idea that species interactions and environmental tolerances translate constrained traits to patterns of species distribution and abundance through a series of trade-offs. First, we suggest a framework to classify relationships among traits at different levels of organization. We then synthesize experiments to quantify relationships at these multiple levels for a group of 11 prairie plant species that characterize different disturbance regimes. Finally, we identify linkages among traits at these different levels and examine how these linkages relate plant traits to patterns of species composition following gap creation.

Linkages were evident between all levels of response, lending credence to the idea that relationships among organismal traits can shape dynamics of species interactions and thereby translate into abundance patterns. Interestingly, the important trade-offs and translators for the set of species we examined were not always the ones predicted by conceptual models. For instance, we found evidence of trade-offs between measures of competitive and tolerance (to soil compaction) abilities, but little evidence of negative correlations between competitive abilities in different environments or between colonization and competitive abilities. Tolerance (to defoliation, shade, drought) and colonization abilities, rather than competitive ability, appeared to be important translators that linked organismal traits to abundance patterns. In addition, growth rates of the species under field conditions, but not other measures of demographic success (e.g., survival, seedbank density), were related to the species distributions due to soil disturbance. Although our results support the idea that trade-offs scale across several levels of organization, specific predictions of several well-known hypotheses are not borne out along all levels of organization and other, less emphasized trade-offs appear to be as important in our study system.
\end{abstract}

Key words: colonization; competition; disturbance; multilevel responses; organismal traits; prairie plant community; specific leaf area (SLA); stress tolerance; trade-offs.

\section{INTRODUCTION}

Trade-offs in performance from one environment to another have been long thought to play a major role in structuring ecological assemblages (Levins and Culver 1971, Mooney 1972, Partridge and Harvey 1988, Gleeson and Tilman 1990, Tilman 1990). Their presumed role stems from the idea that many of the same constraints that shape the evolution of traits of individuals

Manuscript received 9 November 2001; revised 17 May 2002; accepted 1 June 2002; final version received 25 June 2002. Corresponding Editor: S. Lavorel.

${ }^{1}$ Present address: Institute of Arctic and Alpine Research and Department of Environmental, Population, and Organismic Biology, University of Colorado, Boulder, Colorado 80309-0450 USA. E-mail: suding@ colorado.edu

2 Present address: Department of Environmental and Plant Biology, Ohio University, Athens, Ohio 45701-2979 USA. also affect interactions among species, and thereby will influence patterns of community structure and ecosystem function (Chapin 1993, Jones and Lawton 1995, Vincent et al. 1996, Chapin et al. 1997, Díaz and Cabido 2001, Grime 2001, Rees et al. 2001, Lavorel and Garnier 2002). Extensive work has documented how species traits relate to abundance patterns, with the appealing prospect that these relationships can be broadly predictive of how communities will respond to changes in climate, resources, or management (MacArthur and Wilson 1967, Southwood 1988, Grubb 1998, Westoby 1998, Weiher et al. 1999, Grime 2001, among others).

Because trade-offs are central to many hypotheses in ecology, it is important to explicitly identify the linkages by which trade-offs among traits scale to patterns in community structure. At their root, trade-offs 


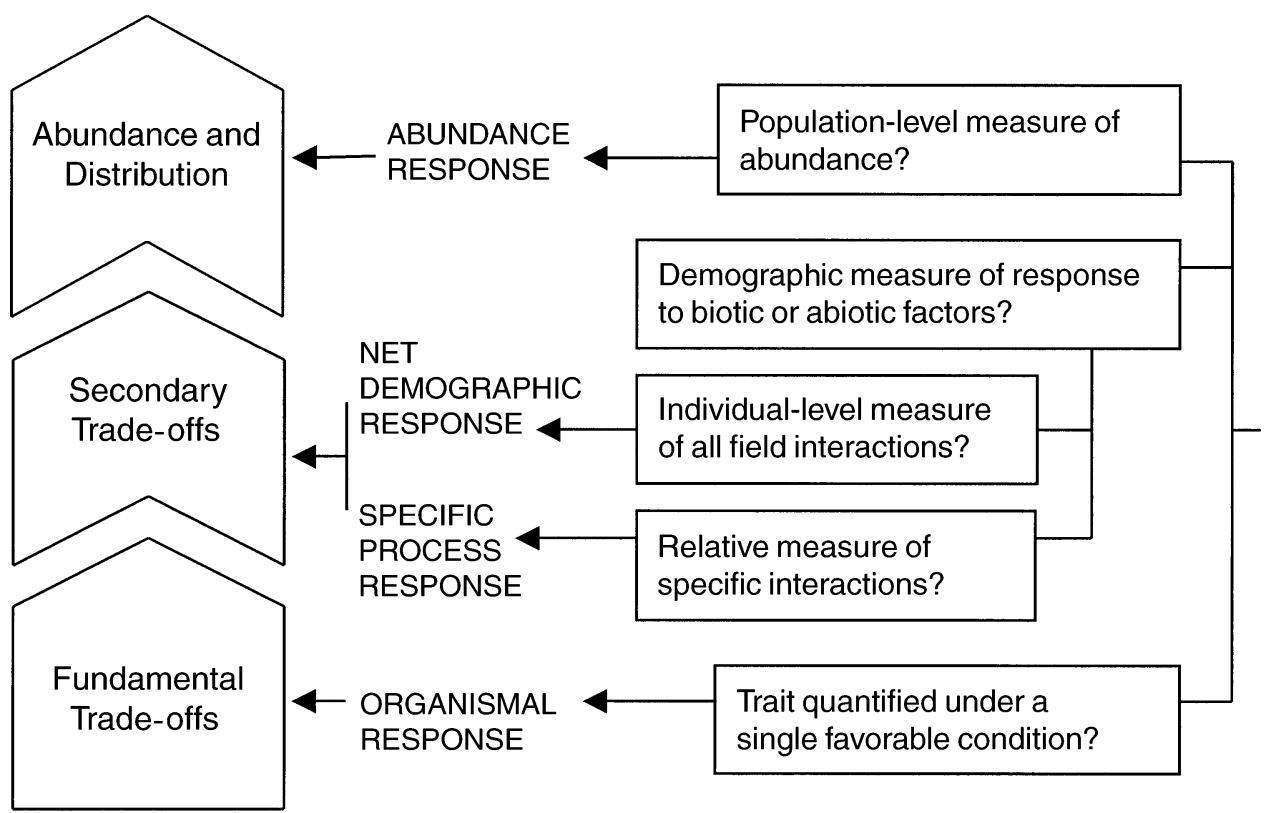

FIG. 1. Operational divisions between four levels of response (organismal, specific process, net demographic, and abundance).

involve genetic or physiological constraints on certain trait combinations (Stearns 1992). These constraints could then shape other trade-offs and trait relationships for an organism. For instance, they could translate to differential abilities to interact with other organisms and/or to tolerate particular environmental conditions (Mooney 1972, Grime 1977, Chesson 1986, Huston and Smith 1987, Tilman 1990, Leibold 1996, McPeek 1996, Tessier et al. 2000). As such, these "secondary" tradeoffs could serve as critical translators between traits and the abundance and distribution of organisms.
Thus, trade-offs are predicted to occur at various levels of organization. Conceptually, these levels can be broken into those traits most constrained genetically (fundamental trade-offs), to those more dependent on biotic and abiotic conditions (secondary trade-offs), and to those describing abundance itself. Operationally, these levels can be separated explicitly into how, and under what conditions, traits are measured and quantified (Fig. 1, Table 1). In addition, it is often presumed that relationships among traits scale along the levels of organization. Here, we suggest four levels at which

TABLE 1. Operational classification of four levels of response.

\begin{tabular}{|c|c|c|c|c|c|}
\hline $\begin{array}{l}\text { Level of } \\
\text { response }\end{array}$ & $\begin{array}{l}\text { Absolute/ } \\
\text { relative } \\
\text { measure }\end{array}$ & $\begin{array}{l}\text { Condition } \\
\text { specific? }\end{array}$ & $\begin{array}{l}\text { Field or } \\
\text { greenhouse } \\
\text { screening }\end{array}$ & Type of interaction & $\begin{array}{l}\text { Measured variables } \\
\text { in this study }\end{array}$ \\
\hline Organismal & $\mathrm{A}$ & less so & $\mathrm{G}$ & few; favorable & $\begin{array}{l}\text { specific leaf area; shoot relative growth } \\
\text { rate (RGR); root RGR; height; root: } \\
\text { shoot ratio; seed germination; seed } \\
\text { mass }\end{array}$ \\
\hline Specific process & $\mathrm{R}$ & more so & $\mathrm{G} / \mathrm{F}$ & specific & $\begin{array}{l}\text { competitive ability in gap and matrix } \\
\text { conditions; tolerance to soil compac- } \\
\text { tion; tolerance to defoliation; toler- } \\
\text { ance to shading; tolerance to drought }\end{array}$ \\
\hline Net demographic & A & more so & $\mathrm{F}$ & all & $\begin{array}{l}\text { seed bank density in gap and matrix } \\
\text { conditions; establishment from seed in } \\
\text { gap conditions; survival in gap and } \\
\text { matrix conditions; RGR in gap and } \\
\text { matrix conditions }\end{array}$ \\
\hline Abundance & $\mathrm{R}$ & more so & $\mathrm{F}$ & all & $\begin{array}{l}\text { relative abundance in mound disturbanc- } \\
\text { es and undisturbed matrix. }\end{array}$ \\
\hline
\end{tabular}

Notes: Each level can be generally characterized by whether it uses relative or absolute measures, varies with environmental condition, is more appropriately screened in the field or greenhouse, and what interactions it quantifies. The last column lists specific variables used in this study (see Methods for more details). "Gap" refers to areas that have been recently disturbed, and "matrix" refers to areas that are relatively undisturbed. 
relationships can be defined and among which linkages could occur. Then, using this structure, we test several well-known hypotheses for plant species trade-offs in a grassland-disturbance system.

\section{Levels of response}

At the most fundamental level, relationships are often expected among organismal responses (e.g., morphology, physiology, life history) due to genetic and physiological constraints. These traits are generally characteristic of the species (i.e., variation among individuals within a species is generally less than variation among species) and are quantified under highly favorable environments, with surplus resources, an absence of negative interactions, and a presence of mutualists.

Due to relationships among organismal traits, species also often differ in the degree to which specific biotic (e.g., predators, competitors, pollinators) and abiotic (e.g., microclimate, soil type, temperature) factors influence their relative fitness. Thus, the ability to deal with a particular isolated process (e.g., competition, colonization, pollination, abiotic stress), a specific process response, should vary among environments and species. Process responses are generally determined experimentally by quantifying one or more demographic parameter(s) under conditions where the process occurs and where it is removed (e.g., comparisons of growth rate in the presence and absence of competitors, comparisons of recruitment with and without the addition of seeds, comparisons of survival with and without predators).

Thirdly, species often vary in their demographic success in natural environments under the net influence of all possible interactions. We refer to this level as net demographic response because these measurements integrate across all processes that influence the demographic fate of an individual within an environment. Although specific process responses are also often measured in demographic terms, they are due to an isolated set of interactions, holding other things constant. In contrast, the sum of all interactions that occur under natural field conditions should determine net demographic response.

Species also often vary in their population dynamics and abundance across environments, which constitutes the final level of response, the abundance response. As opposed to the other levels whose responses are generally per capita, relative abundance is a population level parameter. Explaining this response is often the ultimate goal in ecological research.

\section{Linkages between levels}

Although the lines between these levels are somewhat blurred, the division into levels of organization can be heuristically useful. Empirical work has often focused on linkages between two of these levels, such as the relationships between organismal response and competitive ability (Tilman and Wedin 1991 $a, b$, Gaudet and Keddy 1995, Goldberg 1996), colonization ability (Tilman 1997), or stress tolerance (Westoby et al. 1996). Studies have also linked organismal response to net demographic response (Gross 1984, Thompson et al. 1996), or abundance response (McIntyre et al. 1995, Grime et al. 1997, Reader 1998, McIntyre and Lavorel 2001). In addition, there have been many studies that linked specific process responses to abundance response (e.g., Gross and Werner 1982, Gaudet and Keddy 1995, MacGillivray et al. 1995, Howard and Goldberg 2001).

Relationships need to be carried through several levels of response if they are to influence patterns of species distribution. Linkages between levels of response can be viewed as cascades: benefits (positive correlations) flow down one side whereas costs (trade-offs; negative correlations) at each level create another, parallel, set of linkages. Cascades should be apparent among factors that are important in the eventual determination of a species abundance response; some relationships within a level of response may not relate to another level because they are simply not important in determining abundance under particular conditions.

\section{Disturbance patterns in grasslands}

Patterns relative to disturbance are an excellent system to examine these linkages because changes in plant species abundance with respect to disturbance type and intensity are well documented in a number of systems (e.g., Platt 1975, Harper 1977, Collins and Barber 1985, Hobbs and Hobbs 1987, Gibson 1989, Belsky 1992, Hill et al. 1992, Umbanhowar 1992), and because variation in organismal response is generally thought to be responsible for the abundance patterns (Hanski 1983, Denslow 1985, Caswell and Cohen 1991, Tilman 1994, Lavorel and Chesson 1995, Lavorel et al. 1997). If relationships are linked among the four response levels, trade-offs at the level of organismal response should translate into secondary trade-offs at other response levels and thereby scale up to the abundance response to disturbance (Fig. 2).

The goals of this paper are to operationalize and quantify (1) relationships among traits at several levels of organization and (2) the linkages of these relationships among levels in a grassland disturbance system. For the first of these goals, we test specific predictions about negative correlations at each level of response. To do so, we quantify a variety of responses at each level and conduct multivariate analyses to summarize correlations within each level of response. Then, we address our second goal by examining how relationships at one level of response (as summarized with species scores from multivariate analysis) scale to relationships at other levels of response. By quantifying relationships among all four levels of response, we test whether relationships at one level of response scale up

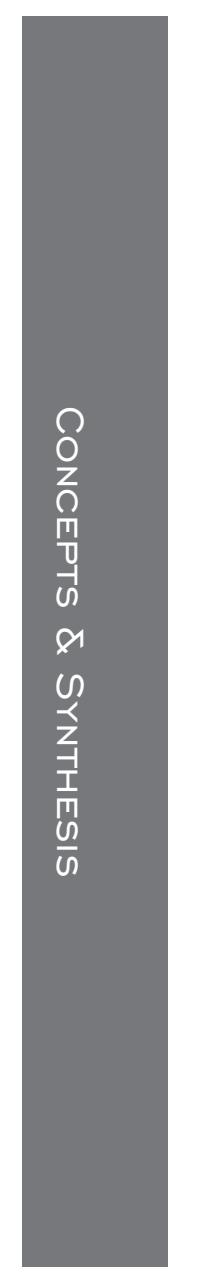




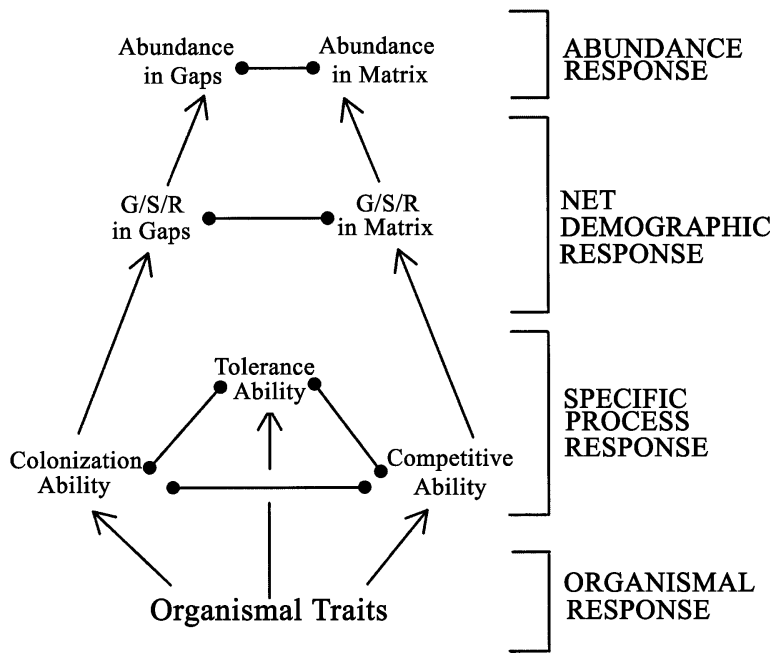

FIG. 2. Hypothesized relationships among the four levels of response in determining the patterns of plant species abundance following creation of a gap disturbance. Arrows indicate linkages and lines indicate trade-offs that are assumed to be most important. "G/S/R" indicates growth, survival and reproduction. "Gap" refers to areas that have been recently disturbed and "matrix" refers to areas that are relatively undisturbed.

through other levels of response along predicted pathways to abundance patterns.

\section{Methods}

We conducted experiments to quantify the responses of plant species that characterize different disturbance regimes of a lake-plain prairie near Castalia, Ohio
(Resthaven Wildlife Area, Ohio Department of Natural Resources). We measured species' responses at each of four levels: organismal response, specific process response, net demographic response, and abundance response (Table 1). We focus on the effects of simulated soil mound disturbances, similar to those created by small mammals, on the species distributional patterns at this prairie. We only synthesize these experiments here; Suding (1999) details the methods and results of the individual experiments and Suding and Goldberg (2001) detail the soil and vegetation characteristics of the matrix and gap environments.

We compared the responses of 11 plant species that characterize different disturbance regimes and growth forms at our study site (Table 2). Although a continuum of species is likely, for clarity we divide the species into species characteristic of undisturbed matrix conditions (matrix species) and species that generally characterize gap conditions (gap species). We refer to the species by their genus or, in figures, by the first letters of the genus and species (e.g., Monarda or MF for Monarda fistulosa).

\section{Organismal responses}

To estimate seed mass, we weighed four groups of 50 seeds collected at the study site for each species. To measure the percentage of seeds germinating, four groups of 50 cold-stratified seeds of each species were also placed in an environmental growth chamber (Labline Instruments, Melrose Park, Illinois) on moist filter paper in closed Petri dishes over a 2 -wk period. The remainder of the traits were determined from plants grown under highly favorable conditions at a green-

TABLE 2. The species used in the experiments, which were characteristic of a range of disturbance regimes and growth forms.

\begin{tabular}{|c|c|c|c|c|}
\hline Species & Abbreviation & $\begin{array}{l}\text { Growth } \\
\text { form }\end{array}$ & $\begin{array}{l}\text { Historic } \\
\text { range }\end{array}$ & Family \\
\hline \multicolumn{5}{|l|}{ Matrix grasses } \\
\hline Andropogon gerardii & AG & $\mathrm{C}_{4}$ grass & native & Poaceae \\
\hline Sorghastrum nutans & $\mathrm{SN}$ & $\mathrm{C}_{4}$ grass & native & Poaceae \\
\hline \multicolumn{5}{|l|}{ Matrix forbs } \\
\hline Coreopsis tripteris & $\mathrm{CT}$ & forb & native & Asteraceae \\
\hline Silphium terebinthinaceum & ST & forb & native & Asteraceae \\
\hline Liatris aspera $\dagger$ & LA & forb & native & Asteraceae \\
\hline \multicolumn{5}{|l|}{ Gap forbs } \\
\hline Monarda fistulosa & MF & forb & native & Labiateae \\
\hline Ratibida pinnata & RP & forb & native & Asteraceae \\
\hline Aster novae-angliae $\dagger$ & AN & forb & native & Asteraceae \\
\hline Daucus carota & DC & forb & naturalized & Apiaceae \\
\hline \multicolumn{5}{|l|}{ Exotic invasives } \\
\hline Agropyron repens $\ddagger$ & AR & $\mathrm{C}_{3}$ grass & exotic & Poaceae \\
\hline Melilotus alba & MA & legume & exotic & Fabaceae \\
\hline
\end{tabular}

Notes: We did not incorporate any grasses that characterized gap conditions in the analyses because they were not abundant at the study site. Nomenclature follows Voss (1972, 1985, 1996).

$\dagger$ These species were not used in the greenhouse process experiments.

\$ These invasive exotic species were not used in net demographic experiments because we did not want to plant them at our study site. 
house at the Matthaei Botanical Gardens (Ann Arbor, Michigan). On 11 August 1998, we planted seeds of each of the 11 species in $80-\mathrm{cm}^{2}$ pots containing soil collected the previous fall from the study site (1 individual/pot). A week later one replicate set of plants was harvested to estimate initial biomass; the remaining six replicates were grown for $82 \mathrm{~d}$. At the harvest, we measured root and shoot biomass (dried to constant mass), shoot height, and specific leaf area (leaf area/ leaf mass). We assumed the plants grew exponentially and calculated relative growth rate (RGR) as the natural $\log$ of [final biomass (at day 82) divided by initial estimated biomass (at day 7)], divided by the growth period (75 days).

\section{Specific process responses}

To assess species process response, we quantified species competitive and tolerance abilities in the greenhouse. We measured competitive ability in both undisturbed and disturbed environments. Seedling target individuals were grown both under undisturbed matrix conditions (compact soil, high neighbor biomass) or gap conditions (loose soil, low neighbor biomass), and with no neighbors at both compact and loose soil conditions. Matrix conditions were simulated by packing the soil into pots to a compaction level equivalent to those found in the undisturbed prairie and planting the neighbors $4 \mathrm{wk}$ prior to the targets. Both types of neighborhoods contained the same neighbor species, the three most abundant species in the matrix prairie ( $A n$ dropogon, Coreopsis, and Sorghastrum). At the end of the experiment (week 12), neighbor biomass was $30 \%$ greater, and the soil was $25 \%$ more compact and contained $20 \%$ more water in the matrix treatment compared to the gap treatment, approximating differences in the field between these two conditions (see Suding and Goldberg 2001). There were six replicates of each species-treatment combination for a total of 216 pots.

We quantified the proportional change in performance due to the presence of neighbors using the natural-log transformed response ratio (ln RR):

$$
\ln \mathrm{RR}_{\text {competition }}=\ln \left(\frac{\text { Growth }_{\mathrm{w} / \text { neighbors }}}{\text { Growth }_{\mathrm{w} / \mathrm{o} \mathrm{neighbors}}}\right) \text {. }
$$

This index was calculated under simulated gap and simulated matrix conditions. Because survival was high and patterns in root and shoot growth were similar, we present competitive ability only in terms of the relative response of total growth.

We assessed species tolerance to four factors that can exert strong effects in grasslands: shade, drought, defoliation, and soil compaction. We planted nine species individually in $9 \mathrm{~cm}$ diameter pots containing soil collected the previous fall from the prairie. After $3 \mathrm{wk}$, we simulated either herbivory, drought, or vertical shading. Each treatment-species combination was replicated seven times. Herbivory (defoliation) was simulated by cutting off half of each leaf. For the drought treatment, we reduced watering frequency by $85 \%$ of that under control conditions. At harvest, soil moisture in the drought treatment was almost $60 \%$ less than the control conditions. For the vertical light treatment, we placed $20 \mathrm{~cm}$ tall black plastic barriers on either side of the pots. Light levels at soil surface were reduced by an average of $30 \%$ by the barriers. To assess the effect of soil compaction, we used the two no-neighbor treatments of the greenhouse competition experiment (soil either loose or compact; see above). After $12 \mathrm{wk}$, we harvested all individuals, separated and weighed above and belowground biomass, and calculated growth rates. Similar to competitive ability, we quantified the effect of each stress with a response ratio:

$$
\ln \mathrm{RR}_{\text {tolerance }}=\ln \left(\frac{\text { Growth }_{\text {stress condition }}}{\text { Growth }_{\text {nonstress condition }}}\right)
$$

where the stress condition consisted of drought, defoliation, compaction, or vertical shading and the non-stress condition consisted of no drought, no defoliation, loose soil, or no shading, respectively.

We define a third type of process response, colonization ability, as the ability to disperse seed to a given environment rather than success once arrived (after Tilman 1990, 1994, but see Grime 2001) in order to separate colonization with seedling competitive or tolerance ability. We did not measure colonization ability per se, and assume that seed size and germination ability indicate the ability to colonize.

\section{Net demographic response}

We examined net demographic response of these species to simulated mound disturbances, similar to those created by small mammals, and to undisturbed areas of the study sites. We describe demographic response using four measures: (1) abundance in the seed bank, (2) ability to germinate, grow and survive starting from seed, (3) ability to grow starting as a seedling outplant, and (4) ability to survive starting as a seedling outplant. All of these components were measured in undisturbed matrix and gap conditions except for the second, which was measured only under gap conditions. We did not use the exotic species (Table 2) in the field experiments because they were rare at the study site. We simulated gaps by digging soil to a depth of $15 \mathrm{~cm}$ in a $50 \mathrm{~cm}$ diameter area, removing the vegetation, and fluffing the soil to form a mound (after Collins 1989).

We measured the seed bank composition of the matrix prairie and an adjacent disturbed field (plowed 3 yr previously) by collecting soil ( 8 cores $2.5 \mathrm{~cm}$ in diameter and $5 \mathrm{~cm}$ deep per replicate), subjecting it to a 4-mo cold treatment to break dormancy, and spreading each sample over sterile Sunshine Mix No. 1 (Sungrow Horticulture, Bellevue, Washington) in 0.4- $\mathrm{m}^{2}$ flats at the Matthaei Botanical Gardens (Ann Arbor, Michigan). Emerging seedlings were censused every 2 wk for 8 wk. To measure the ability of species to emerge and persist from seed in the field, we sowed

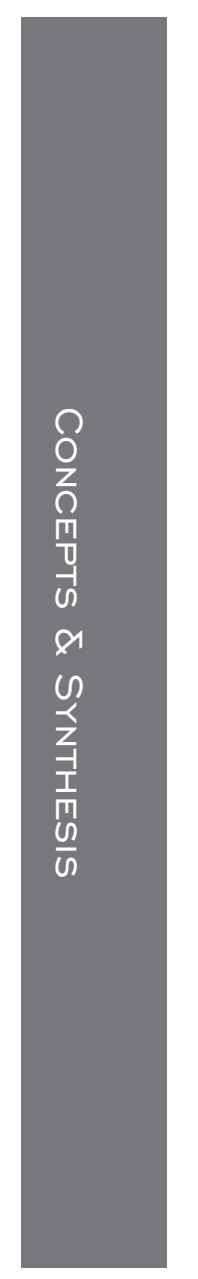


100 viable seeds of each species in each of eight simulated mounds on 30 May 1997. Species biomass was harvested on 10-13 August 1998, dried to a constant mass, and weighed.

To measure individual seedling growth and survival, three conspecific seedlings of each nine target species in each disturbance condition (simulated gap, undisturbed matrix) were planted in eight replicate blocks on 28 May 1997. This was part of a larger experiment detailed in Suding and Goldberg (2001). First year shoot relative growth was defined as the difference between the aboveground biomass of the target at the firstyear harvest on 16-18 September 1997 (when one of the seedlings was harvested or, in cases of low survival, estimated from biomass regressions) and initial planting (estimated), divided by the initial target mass. Final shoot relative growth was measured as the difference in the aboveground biomass of the target at the final harvest on 19-20 September 1998 (weighed) and initial planting, divided by the initial target mass. We measured target survivorship separately for 1997 and for 1998.

\section{Abundance response}

During May 1997 we established 26 pairs of plots, each with a matrix undisturbed plot and an adjacent simulated mound plot. We allowed natural colonization for two growing seasons, and during 20-23 August 1998 we visually estimated species cover in each plot using a cover index (Braun-Blanquet 1932).

\section{Analysis}

To reduce the many variables measured for each level of response to a few composite variables that summarize variation among species, we conducted principal component analyses (PCAs) for each level of response (organismal, process, net demographic, abundance). We ranked each species mean response for each variable to linearize responses and eliminate any possible influence of different measurement scales on the analysis. Within a response level, only species whose responses were measured in all experiments could be included, restricting the overall analysis to nine species in the specific process PCA and nine species (seven of the previous species) in the net demographic response PCA; all species $(n=11)$ were represented in the organismal response PCA and abundance response PCA. Axes were rotated using the varimax algorithm in SYSTAT 5.03 for Windows (Systat 1991).

Within a level of response, we show the first four multivariate axes of the PCA analyses, except for abundance response in which we use the first two axes. Because selection of variables can influence the reported importance of an axis, we base conclusions on the relationships each axis described rather than the amount of variation explained. Traits with high loadings on an axis are those that explain a large proportion of the variation among the species for that axis. Neg- ative correlations among species traits (which we interpret as evidence of trade-offs) are present when two traits have high loadings on an axis, but in opposite directions. Because the axes are orthogonal, we interpret traits to vary independently of one another if they have high loadings on different axes.

Correlations among multivariate axes from different levels of response indicate how relationships may scale up to other levels. This approach has low statistical power because of the many possible comparisons to be made (three groups of four axes each, and one group of two axes) and the relatively low number of data points (seven to nine species). The significance level for each comparison was adjusted with a Bonferroni experimentwise error rate, although because statistical power was low, we also show trends that are significant without adjustment.

\section{RESUlts}

\section{Relationships within each response level}

The PCA at the organismal response level indicated strong correlations between many species traits (Fig. $3 \mathrm{~A})$. The first axis accounted for $>42 \%$ of the variance; high scores reflect species with a suite of traits represented by fast shoot and root growth rate, tall stature, and high specific leaf area. The second axis explained an additional $19 \%$ of the variance, mostly representing a trade-off from shoot allocation to root allocation. The third and fourth axis, each describing $\approx 16 \%$ of the variance, describe species variation in seed traits (Fig. 3B). The third axis encompasses variation in seed mass and an interesting trade-off between seed mass and specific leaf area. Seed viability is described by the fourth axis; species with high scores on this axis had high germination percentages. Because the combination of seed mass and viability is generally thought to indicate colonization ability, we calculated a composite axis that combined the values of the third and fourth axes (i.e., projected scores on an axis that split the second and fourth quadrants of Fig. 3B) to use in further analyses (organismal response axis 3-4).

Results at the process response level indicate that competitive ability (axes 1 and 2), defoliation tolerance (axis 3), and shade and drought tolerance (axis 4) are somewhat independent because variation in these traits is described by separate axes (Fig. 4). The first and second axis, explaining $30 \%$ and $17 \%$ of the variance, respectively, separate competitive ability in gap and matrix conditions. Surprisingly, there is no apparent trade-off between the two; competitive abilities in these two environments are independent of each other and are described by two different axes. Competitive ability in gap conditions is negatively correlated with tolerance to soil compaction (process response axis 1): the species that are good response competitors under gap conditions do not tolerate soil compaction, a condition that characterizes matrix conditions. The third axis, 

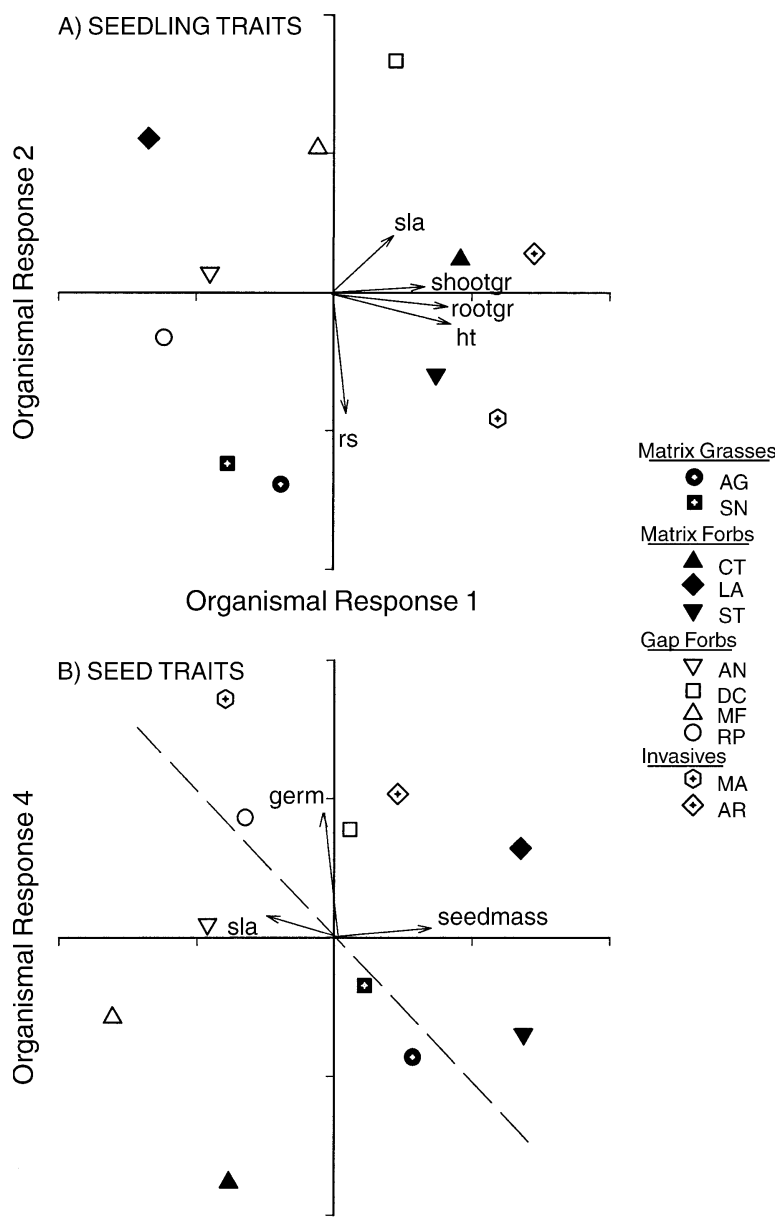

Organismal Response 3

FIG. 3. Principal components for traits at the level of organismal response. Each symbol represents a species; see Table 2 for plant name abbreviations. The endpoints of the arrows indicate component loadings for each of the variables; traits with loadings $>0.5$ for at least one axis are shown on a particular graph. Trade-offs, negative correlations among species traits, are present when two traits have high loadings on an axis, but in opposite directions (e.g., SLA and seed mass on axis 3). Because the axes are orthogonal, we interpret traits to be independent of one another when they have high loadings on different axes. (A) The first two rotated axes, describing seedling traits, explain $42 \%$ and $19 \%$ of the variance, respectively. (B) The third and fourth axes, describing seed traits, each explain an additional $16 \%$ of the variance. Abbreviations: sla, specific leaf area; shootgr, potential shoot relative growth rate; rootgr, potential root relative growth rate; ht, final height; rs, root:shoot ratio; germ, percent germination; and seedmass, seed mass.

accounting for another $23 \%$ of the variation, reflects tolerance to defoliation, which is independent from a species' tolerance to shade and drought (process response axis 4). It is noteworthy that the response to drought and shading are negatively correlated among these species, because drought conditions are characteristic of gap conditions, whereas shaded conditions are characteristic of matrix conditions in this system.
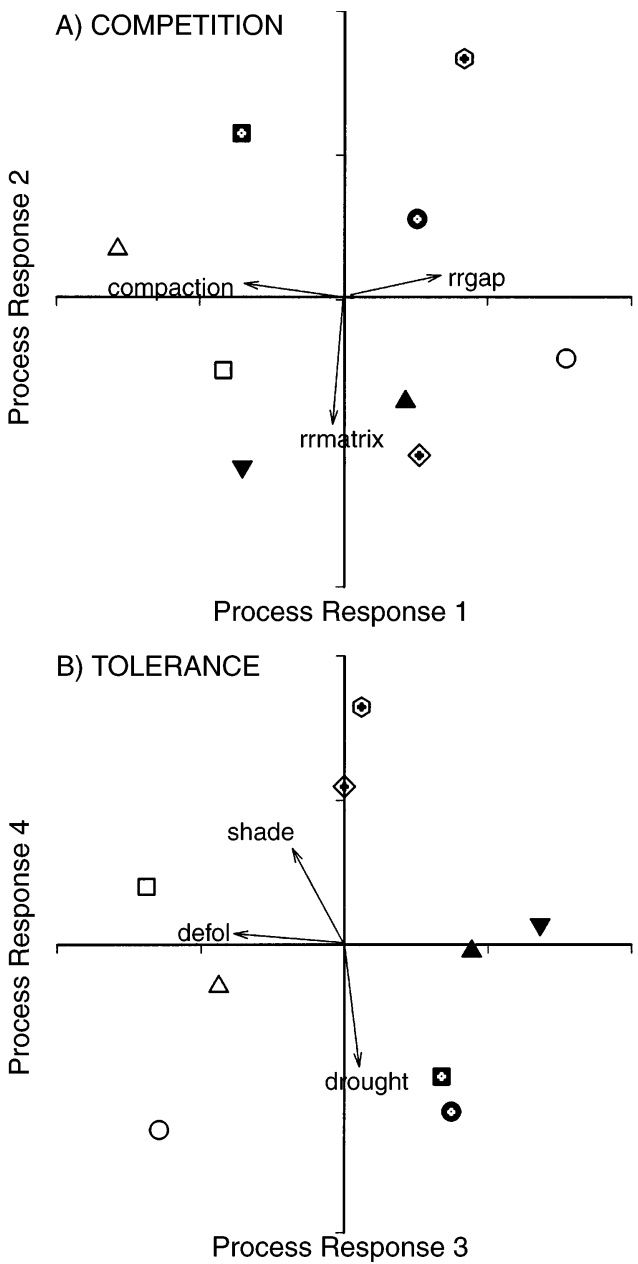

FIG. 4. Principal components for specific process response measures. The structure follows Fig. 3. (A) The first two axes describe response competitive ability, in simulated gap conditions (30\% of variance) and in matrix conditions (17\% of variance). (B) The third and fourth axes, explaining $23 \%$ and $26 \%$ of the variation, respectively, describe tolerance to defoliation and tolerance to drought and shade conditions. Abbreviations: rrgap, relative response competitive ability under simulated gap conditions; rr matrix, relative response competitive ability under simulated matrix conditions; compaction, tolerance to soil compaction; defol, tolerance to defoliation; drought, tolerance to drought; shade, tolerance to shaded conditions.

In the third level of response, net demographic response, the first PCA axis explained nearly $50 \%$ of the variance; high scores indicate high growth rate under both gap and matrix conditions (Fig. 5A). The second axis, accounting for an additional $25 \%$ of the variance, explained variation in seed bank numbers (regardless of origin) and survival response under matrix conditions during the second year. The third and fourth response axes explain less variation $(14 \%$ and $6 \%$, respectively). These two axes account for additional variation in survival under matrix conditions (axis three) and survival under gap conditions (axis four; Fig. 5B). 

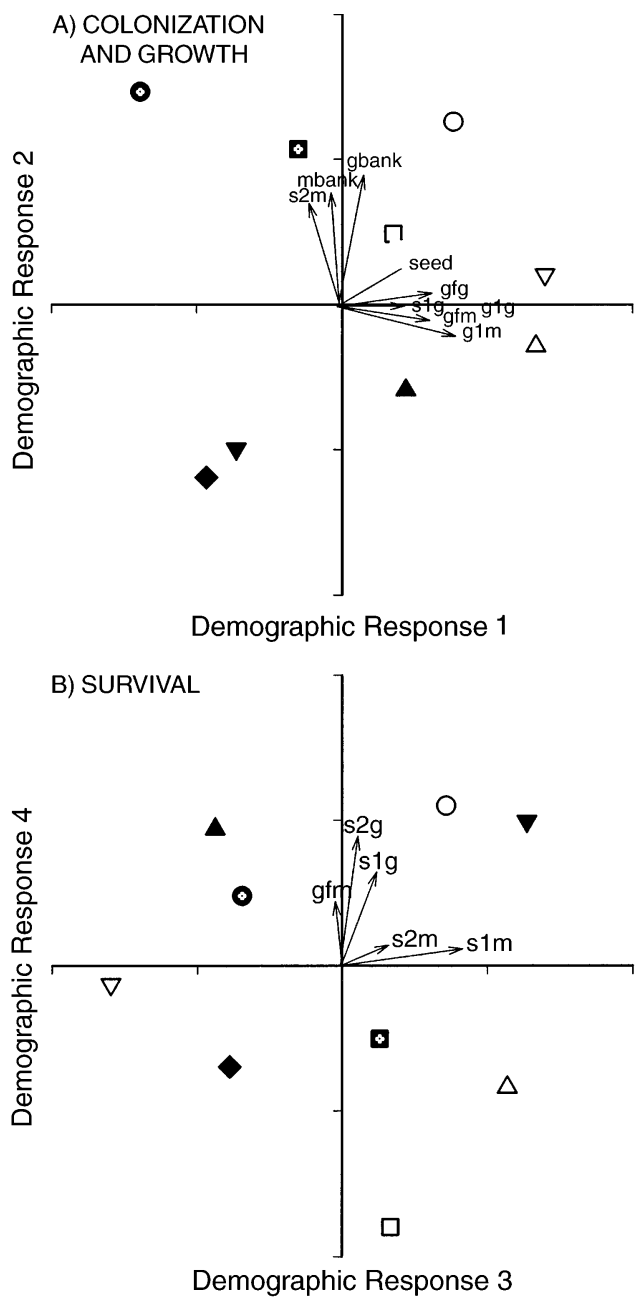

FIG. 5. Principal components that describe the variation in species response in net demographic response experiments. The structure follows Fig. 3, although invasive species were not used in these experiments. (A) The first two axes describe growth and colonization (seed bank) response in the field and explain $50 \%$ and $25 \%$ of the variance, respectively. (B) The third and fourth axes, describing survival in matrix and gap conditions respectively, explain $14 \%$ and $6 \%$ of the variation. Abbreviations: gbank, gap field seed bank density; mbank, matrix seed bank density; seed, germination and establishment of added seeds; gfg, final relative growth of outplanted seedlings in gaps; gfm, final seedling relative growth in matrix; g1g, first-year seedling relative growth in gaps; g1m, first-year seedling relative growth in matrix; s1g, proportion seedling survival in the first year in gaps; $\mathrm{s} 1 \mathrm{~m}$, proportion seedling survival in the first year in matrix; $\mathrm{s} 2 \mathrm{~g}$, second-year juvenile survival in gaps; and s2m, second-year juvenile survival in matrix.

Survival was the only parameter in which the response in matrix conditions was independent of the response in gap conditions; different axes explain variation under each condition. All other demographic parameters exhibited positive, rather than the predicted negative, correlations between undisturbed and disturbed con- ditions, indicating that there are no trade-offs between environments for these variables.

For abundance response, trade-offs in species distribution between gap and matrix environments are described by the first PCA axis (Fig. 6), explaining 42\% of the variance. Our qualitative categorization of gap and matrix species (e.g., Table 2) is supported by this analysis. The second PCA axis explained less variance, only $18 \%$ of the total, and appears to relate to the variation in abundance within a disturbance environment. We do not include other axes because they have very little explanatory value.

\section{Linkages between response levels}

Of the 44 potential correlations between multivariate axes at one response level and multivariate axes at the subsequent response level, only six were significant or marginally significant (Table 3 ). There were an additional 38 possible correlations between axes for response levels that are nonsequential (e.g., between organismal and demographic responses); almost $20 \%$ of these relationships were significant or marginally significant. In general, the lack of significant relationships among different response levels is surprising, although the power of this analysis is low due to the number of species used in the experiments.

Two sets of cascades were apparent in this analysis, one explaining variation in the distribution of species between gap and matrix plots (abundance response 1) and one explaining variation in abundance within a disturbance type (abundance response 2). The first cascade (Fig. 7) suggests linkages between seed traits (the composite organismal response 3-4), tolerance to defoliation (process response 3), growth in the field (demographic response 1) and distribution in gap and matrix environments (abundance response 1). Specifically, species with high specific leaf area, low seed mass, and high germinability tended to be tolerant to defoliation. This same set of species tended to grow quickly in field conditions (gap or matrix conditions), and to be more abundant in gap environments than in matrix environments. In contrast, the species with low specific leaf area, heavy seeds, and low germinability were intolerant to defoliation, grew slowly in the field, and characterized undisturbed conditions.

The second cascade (Fig. 8) linked maximal growth rates (organismal response 1), drought and shade tolerance (process response 4), seedbank density (demographic response 2) to within-environment abundance (abundance response 2). Species with fast maximal RGR were intolerant to drought, tolerant to shade, not well represented in the seedbank, and tended to be subordinate.

\section{DISCUSSION}

Empirically identifying the links between organismal, specific process, net demographic, and abundance responses is an approach that takes into account how 


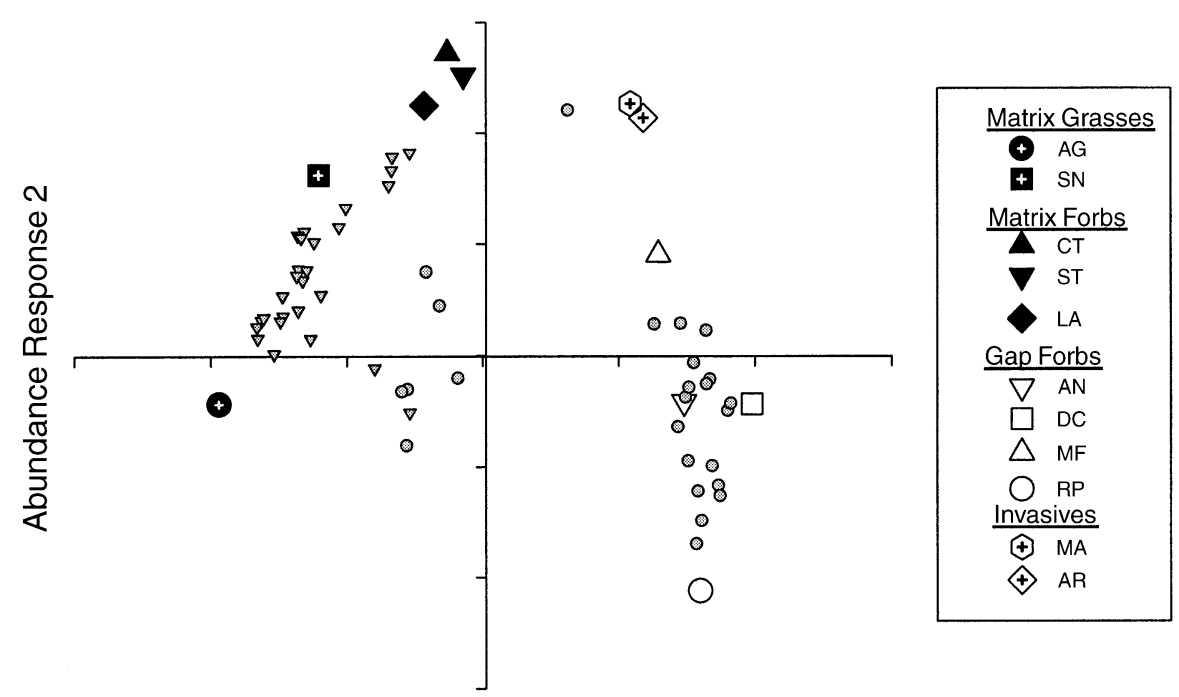

Abundance Response 1

FIG. 6. Abundance patterns in undisturbed matrix and simulated gap plots as described by principal correspondence analysis. The shaded symbols represent plot loadings; triangles are plots located in matrix (undisturbed areas), and circles are plots located in soil disturbances. The first axis describes the distribution of species in matrix and gap environments and explains $42 \%$ of the variance. The second axis explains $18 \%$ of variance and describes local abundance patterns. See Table 2 for plant name abbreviations.

TABLE 3. Relationships among levels of response.

\begin{tabular}{|c|c|c|c|c|c|c|c|c|c|c|c|c|c|}
\hline \multirow[b]{2}{*}{ Response } & \multicolumn{5}{|c|}{ Organismal } & \multicolumn{4}{|c|}{ Specific process } & \multicolumn{4}{|c|}{ Net demographic } \\
\hline & $\mathrm{O} 1$ & $\mathrm{O} 2$ & $\mathrm{O} 3$ & $\mathrm{O} 4$ & $\mathrm{O} 3-\mathrm{O} 4$ & $\mathrm{P} 1$ & $\mathrm{P} 2$ & P3 & $\mathrm{P} 4$ & D1 & D2 & D3 & D4 \\
\hline \multicolumn{14}{|l|}{ Organismal response $(\mathrm{O})$} \\
\hline \\
\hline \multicolumn{14}{|l|}{ O2. Root allocation (-shoot allocation) } \\
\hline \multicolumn{14}{|l|}{ O3. Specific leaf area (-seed mass) } \\
\hline \multicolumn{14}{|l|}{ O4. Seed germination } \\
\hline \multicolumn{14}{|l|}{ O3-O4. Colonization ability proxy } \\
\hline \multicolumn{14}{|l|}{ Specific process response $(\mathrm{P})$} \\
\hline $\begin{array}{l}\text { P1. Competitive ability gap conditions } \\
\text { (-tolerance to soil compaction) }\end{array}$ & & $\ldots$ & $\ldots$ & $\cdots$ &. & & & & & & & & \\
\hline P2. Competitive ability matrix condition & Is & $\ldots$ & $\ldots$ & $\ldots$ & + & & & & & & & & \\
\hline P3. Tolerance to defoliation & $\checkmark$ & $\ldots$ & $\ldots$ & $\ldots$ & $(+)$ & & & & & & & & \\
\hline $\begin{array}{l}\text { P4. Tolerance to drought (-tolerance to } \\
\text { shade) }\end{array}$ & $\begin{array}{c}(-) \\
1\end{array}$ & $\ldots$ & & & $\dddot{1}$ & & & & & & & & \\
\hline Net demographic response (D) & i & & & & $\downarrow$ & & & $\downarrow$ & & & & & \\
\hline D1. Growth gap and matrix environment & 1 & ... & $(+)$ & ... & $(+)$ & $\ldots$ & $\ldots$ & $(+)$ & $\frac{1}{\gamma}$ & & & & \\
\hline D2. Seed bank density & $\frac{1}{1}$ & $\cdots$ & ... & $\cdots$ & 1 & $\ldots$ & $\ldots$ & $\dddot{1}$ & $(+)$ & & & & \\
\hline D3. Survival in matrix environment & +1 & ... & $\cdots$ & $\ldots$ & i. & $\cdots$ & $\cdots$ & 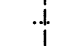 & 1. & & & & \\
\hline D4. Survival in gap environment & it & $(+)$ & $\ldots$ & . & +1. & $\ldots$ & $\cdots$ & + & t.. & & & & \\
\hline Abundancce response $(\mathrm{A})$ & 1 & & & & $\downarrow$ & & & 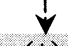 & & $v$ & & & \\
\hline $\begin{array}{l}\text { A1. Abundance matrix environment } \\
\text { (-abundance gap environment) }\end{array}$ & $\frac{1}{\downarrow}$ & & & & $(-)$ & $\ldots$ & ... & $(+)$ & 1 & $(-)$ & 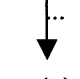 & ... & \\
\hline $\begin{array}{l}\text { A2. Local (within environment) } \\
\text { dominance }\end{array}$ & $(-)$ & (.. & & $\therefore$ & $\ldots$ & $\ldots$ & $\cdots$ & $\ldots$ & $(+)$ & ... & $(-)$ & $\cdots$ & \\
\hline
\end{tabular}

Notes: For each level of response, the principal component axes are labeled with the trait(s) that they best describe. Correlated traits within a response level (e.g., O3: SLA and seed mass) are indicated in parentheses. Significant correlations between axes from different levels of response are indicated by a plus or minus sign (see Figs. 7 and 8 for $R^{2}$ values). A plus sign indicates positive relationships among these variables, and a minus sign indicates negative relationships. Depending on how the response variable is related to the PCA axis (see Figs. 3-6), this sign (+ or -) may not be indicative of the correlation among axis scores (see Figs. 7 and 8). Solid arrows indicate potential linkages among sequential levels of response, and dashed arrows (and the shaded region) indicate potential links to abundance that skip levels of response. 


\section{Matrix Grasses Gap Forbs}

- AG

* SN

$\nabla \quad$ AN

$\square \quad D C$

$\triangle \mathrm{MF}$

Matrix Forbs

$\triangle \mathrm{CT}$

$\bullet \quad$ LA

$\nabla \mathrm{ST}$

$\underline{\text { Invasives }}$

$\stackrel{A}{A} \mathrm{AR}$

(4) $\mathrm{MA}$

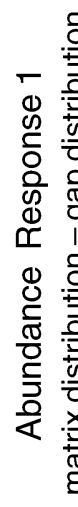

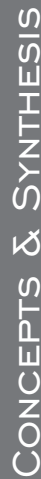

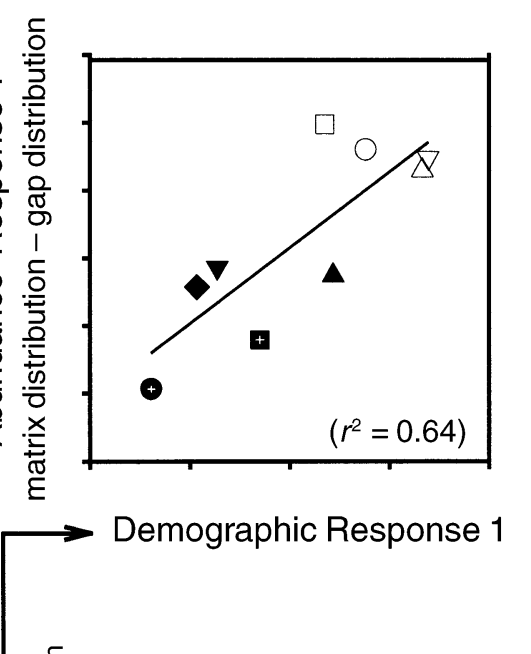

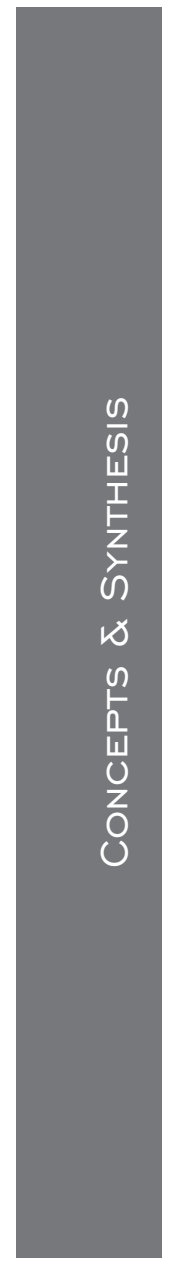
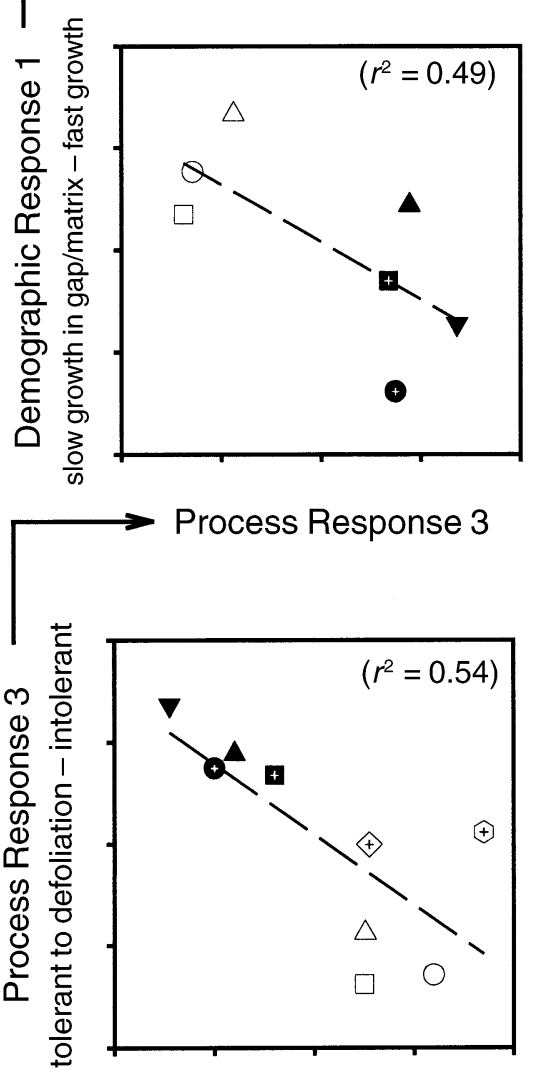

Organismal Response 3-4 heavy seed - high SLA/germination poor colonizer - good colonizer

relationships among traits ultimately translate into the distribution and abundance of organisms. Our results largely validate the idea that plant traits are related to one another through a series of linkages to influence species distribution patterns. Indeed, relationships between these factors appear to be predictable and have a mechanistic basis. However, it also appears that individual traits can affect abundance patterns through multiple pathways, and at times may even skip levels.

In examining the relationships between several ecological linkages simultaneously, some strengths of other investigations are sacrificed. Although nine is a large number of species to include in plant competition and field transplant experiments (see Goldberg and Barton 1992), it is small in comparison to the number of plant species used in many trait-screening experiments (e.g., Swanborough and Westoby 1996, Grime et al. 1997, Craine et al. 2001, Vendramini et al. 2002). Because of the number of species used and the attempt to describe a particular abundance response, we were not able to account for the role of phylogeny in determining these patterns (Givnish 1987, Armstrong and Westoby 1993) and the species used represent a fairly narrow functional set (i.e., herbaceous perennials).

We chose to concentrate on seedling and juvenile responses because they have been found to be important for determining the abundance and persistence of populations (Harper 1977, Fenner 1985, Grubb 1985). All measures were taken on species grown for months in the greenhouse or during a few growing seasons in the field. We do not consider adult responses, such as pollination success or clonal growth, that clearly have the potential to affect plant community dynamics. It can be argued that the absence of an expected tradeoff or linkage in this study could be due to the trait being measured in the wrong setting (i.e., in the greenhouse rather than field) or at the wrong life history stage (i.e., with seedlings rather than adults), or that an important trait was not measured at all. Our results could be strongly influenced by these possibilities and should be interpreted within the context of the traits we measured and the conditions under which we measured them.

\section{Comparison with conceptual models}

Three well-known conceptual models predict how organismal traits translate to abundance patterns: the

FIG. 7. A cascade of relationships from organismal response (bottom graph) that ultimately lead up to abundance response 1 (top; matrix/gap species distribution). Arrows indicate linkages between levels (i.e., the same variable on the $y$-axis is on the next graph on the $x$-axis). Species scores are from multivariate axes; $R^{2}$ values are reported on each graph. Solid regression lines indicate statistically significant correlations after Bonferroni correction; dotted regression lines indicate significant relationships prior to correction. See Table 2 for plant name abbreviations. 

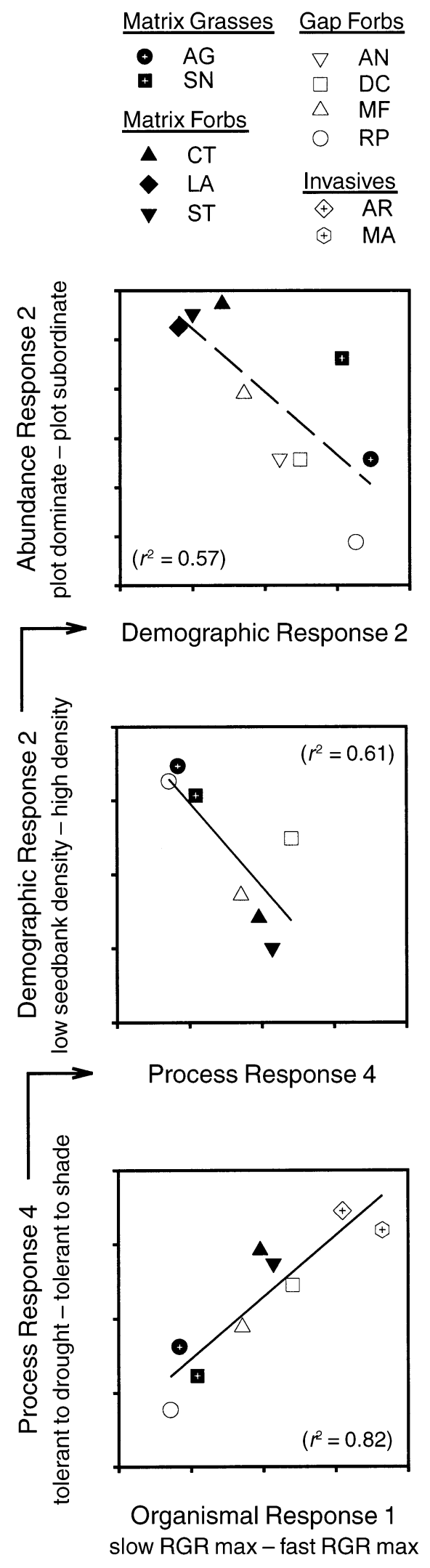

resource ratio hypothesis (Tilman 1988), competitive/ stress-tolerant/ruderal (C/S/R) strategy (Grime 1979), and $r / K$ selection (MacArthur and Wilson 1967, Pianka 1970) (Table 4). While these models in their original form are very general, a common variation of these themes has been applied to disturbance-generated patterns (e.g., Harper et al. 1970, Levins and Culver 1971, Huston 1979, Denslow 1985, Caswell and Cohen 1991, Aerts and van der Peijl 1993, Elberse and Berendse 1993, Lavorel and Chesson 1995, Lavorel et al. 1997, Westoby 1998). Each model generates predictions about trait relationships within each level of response and the linkages among levels leading to disturbance patterns. The examples in Table 4 are relatively simple; dimensionality quickly increases when different environments and life history stages are considered.

While our results do not completely support any of the three models, they lend partial support to some of the predictions and suggest other important trade-offs and linkages that may have been overlooked. Interpretation of the results also highlights the problem of inconsistent definitions among models, particularly at the level of process response.

We found evidence for many of the trade-offs in organismal response predicted by the three models. Among the group of species we examined, the species with heavy seeds had low specific leaf area, and vice versa. This relationship has ties to the trade-off between leaf longevity and seed production predicted by the Grime's C/S/R model: lower specific leaf area is often related to a longer leaf life-span (Poorter 1994) and light seed mass is often related to high seed production. While we did not find evidence of a trade-off between allocation to reproduction and allocation to growth, as predicted by MacArthur and Wilson's $r / K$ model, other studies with larger numbers of species have found this trade-off (Grime and Hunt 1975, Fenner 1978, Grime et al. 1988, Jurado and Westoby 1992, Swanborough and Westoby 1996; see Shipley and Peters 1990 for an exception). Because SLA is often indicative of fast growth rates (Poorter and Remkes 1990, Reich 1993, Swanborough and Westoby 1996, Westoby 1998), the trade-off between SLA and seed size could be an indication of the trade-off between growth and reproductive allocation. Species also varied in their root-toshoot allocation, the trade-off the Tilman model assumes to be important.

At the process response level, both the C/S/R and $r / K$ models (as well as Tilman 1990) predict a trade-off

FIG. 8. Relationships between different levels of response that may explain abundance response 2 (top; variation in local abundance). Values are from multivariate axes; $R^{2}$ values are reported on each graph. Solid regression lines indicate significant correlations after Bonferroni correction; dotted lines indicate significant correlations prior to correction.

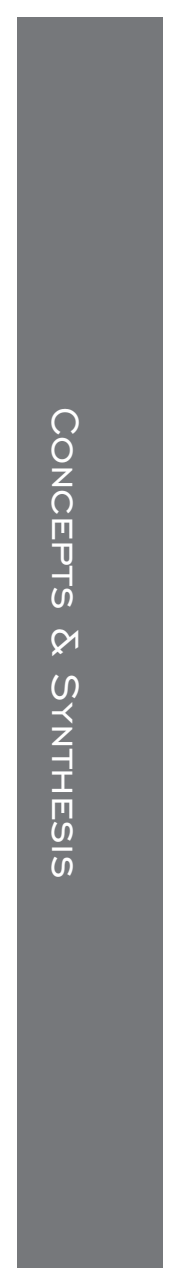


TABLE 4. Predictions of trade-offs within each level and linkages among levels from three general conceptual models, adapted from their original form to relate to plant species abundance following disturbance.

\begin{tabular}{lll}
\hline \hline A. Tilman (1998): the resource ratio hypothesis & Allocation to shoot mass \\
$\mathrm{O} \quad$ Allocation to root mass & Competitive ability for soil resources & Competitive ability for light \\
$\mathrm{NDR}$ & $\mathrm{G} / \mathrm{S} / \mathrm{R}$ in infertile soils & $\mathrm{G} / \mathrm{S} / \mathrm{R}$ in rich soils \\
$\mathrm{ARR}$ & Rel ab early succession & Rel ab late succession
\end{tabular}

B. Grime (1979): $C, S$ and $R$ selection

$\begin{array}{lllll}\text { OR } & \text { Leaf longevity } \longrightarrow \text { RGRmax } & \text { Seed production } \\ \text { SPR } & \text { Stress tolerance } & \text { Competitive ability } & \text { Colonization ability } \\ \text { NDR } & \text { G/S/R stressful habits } & \text { G/S/R benign habitats } & \text { G/S/R disturbances } \\ \text { AR } & \text { Rel ab stressful habitats } & \text { Rel ab benign habitats } & \text { Rel ab disturbances }\end{array}$

C. MacArthur and Wilson (1967) and Pianka (1970): $r$ and $K$ selection

OR Allocation to reproduction

SPR Colonization ability

NDR Growth at low density

AR Rel ab early succession $\longleftrightarrow$ Allocation to growth

Competitive ability

Survival at high density

Rel ab later succession

Note: The response levels are abbreviated as follows: OR, organismal response; SPR, species specific process response; NDR, net demographic response; and AR, abundance response; "Rel ab" indicates relative abundance and "G/S/R" indicates growth, survival, and reproduction.

between competitive and colonization ability. Although we did not directly measure colonization ability, we interpret the composite organismal response axis 3-4 as approximating species' abilities to colonize. In contrast to the predictions, this measure of colonization was not related to species' competitive ability. However, the definition we use for colonization ability, the ability to disperse seed to a given environment, does not take in account the success of the seed/seedling once arrived, as would the definition used by the Grime model. Differing views concerning what constitutes colonization ability could influence this result.

Another inconsistency among the models concerns definitions of competitive ability. Tilman's resource ratio model and MacArthur and Wilson's $r / K$ model assume that competitive ability is a long-term measure at population equilibrium. We use short-term measures of competitive ability, more similar to the way the Grime model construes competitive ability (Goldberg 1990, but see Grime 2001). These differences in definitions may resolve the lack of relationships with competitive ability, particularly for predictions made by the resource ratio and $r / K$ models. For instance, we found that competitive ability in gap and matrix environments (presumably for soil resources and light, respectively) were largely independent from each other, in contrast to the Tilman model predictions, but also based on a short-term measure of competitive ability. The tradeoff between competitive ability in gap conditions and tolerance to soil compaction, a stress in matrix conditions, supports the Grime model.

The interpretation of results regarding the correlation between potential growth rate and shade tolerance also illustrates inconsistencies among the models. The Tilman model, but not the Grime or $r / K$ models, would consider shade tolerance indicative of competitive ability for light and, given this, our results would support a linkage between potential growth rate and competitive ability, predicted by the other two models. When using the Tilman interpretation of shade tolerance as a form of competitive ability, our results would also indicate a trade-off between competitive ability and tolerance (to drought), predicted by the Grime model. 
We found few relationships at the level of net demographic response. Both the Grime and Tilman models predict that different demographic parameters (e.g., growth, survival, reproduction) are positively correlated with one another, and that the major demographic trade-offs are between different environments. The MacArthur and Wilson model predicts a negative correlation between growth in gap environments and survival in matrix environments. In opposition to predictions from all three models, we found that species growth and survival are largely independent of one another and that growth patterns are similar in gap and matrix environments. Patterns in species relative growth in the field did correlate strongly to disturbancegenerated abundance patterns, supporting the widespread use of growth measures to assess differential fitness, although not the underlying reason for its use (i.e., that other fitness measures are positively correlated with growth).

Despite inconsistent definitions, relationships among responses were not as prevalent in this study as generally predicted. It is likely that more exist, but we were only able to identify the most general and simple. The relationships we identified had to be general among all functional groups (we would have missed those that were only present among grasses, for instance) and between two sets of traits (we would have missed threeway trade-offs). However, multidimensional relationships among particular functional groups may be as (or more) prevalent as the trade-offs we did identify. These ideas are inherent to three-way strategy models such as the Grime C/S/R model. Tilman (1990) also has come to this conclusion at the level of process response, suggesting a three-way trade-off among colonization, competition for nutrients, and competition for light, in which the importance of the trade-offs shift during succession.

\section{Linkages}

In addition to predicting relationships among traits at each level of response, each model also predicts that certain types of responses are related to one another across levels, forming cascades that relate organismal response to abundance patterns following disturbance. The most noteworthy aspect of this analysis is that it did not include competitive ability as an important translator. No organismal response measured was a good predictor of competitive ability, nor was competitive ability a good predictor of aspects of net demographic response. Other studies have found that competitively superior species under particular conditions do share particular traits (e.g., lower vegetative growth rate, higher root allocation, Tilman and Wedin $1991 b$; larger seed size, Gross and Werner 1982, Goldberg and Werner 1983, Gross 1984, Crawley and Nachapong 1985) and have lower tolerance abilities (dry soil, Cook 1965; drought, Sharitz and McCormick 1973). These relationships are not consistently iden- tified among studies, suggesting that they may depend on such factors as productivity, size structure, or community type.

In this study, we found tolerance (to shade, drought, and defoliation) and colonization ability better translated organismal responses to field demography than did competitive ability. Tolerance to defoliation, in particular, was an important translator between organismal responses and demographic and abundance patterns due to disturbance. The regrowth capacity of an individual following herbivory may be very different from the ability to resist or avoid herbivory, and may be associated with fast growth rates under field conditions. In contrast, we found that fast growth rates under greenhouse conditions were associated with the ability to tolerate shade and the inability to tolerate drought.

Although we did find complete cascades, there was also evidence of relationships between nonadjacent levels with no intermediate translator. Are there reasons to expect linkages ever to skip response levels? Skipped levels may indicate a missing link. Alternatively, linkages that skip levels may indicate that responses do not always scale up, and that there are alternative ways by which responses can be translated to abundance patterns. With an infinite number of responses that could be measured, it will be difficult to distinguish between these two possibilities.

\section{Conclusions}

This study contributes to a growing conceptual framework that links traits to patterns of abundance in several ways. First, we suggest an approach to explicitly identify and test linkages among traits at various levels of organization. Second, in our model system, we found that many of the predicted linkages were absent. For instance, competitive ability, at least the individual-based measure we used, was of little predictive value. Other trade-offs, which are often not emphasized in the conceptual literature, appear to be important in generating species distributional patterns following a disturbance. Finally, we identified a series of linkages among levels of response that may translate variation in organismal traits into patterns of field abundance. These linkages substantiate ideas that secondary trade-offs involving species interactions translate constraints on organismal traits to species distributional patterns.

\section{ACKNOWLEDGMENTS}

The National Science Foundation (DEB 97-01250) and University of Michigan (Helen Olson Brower Memorial Fellowship, Rackham Predoctoral Fellowship) funded this research. K. N. Suding was supported by the Andrew W. Mellon Foundation while writing this manuscript. We thank S. Fielder and D. Schoolmaster for field assistance. Comments from S. Díaz, J. P. Grime, S. Lavorel, M. Leibold, R. Michalet, G. G. Mittelbach, T. Rajaniemi, B. Rathcke, L. Schiesari, S. Sherrod, and E. E. Werner greatly improved this paper. 


\section{Literature Cited}

Aerts, R., and M. J. van der Peijl. 1993. A simple model to explain the dominance of low-productive perennials in nutrient-poor habitats. Oikos 66:144-147.

Armstrong, D. P., and M. Westoby. 1993. Seedlings from large seeds tolerate defoliation better-a test using phylogenetically independent contrasts. Ecology 74:10921100.

Belsky, A. J. 1992. Effects of grazing, competition, disturbance and fire on species composition and diversity in grassland communities. Journal of Vegetation Science 3: 187-200.

Braun-Blanquet, J. 1932. Plant sociology: the study of plant communities. McGraw-Hill, New York, New York, USA.

Caswell, H., and J. E. Cohen. 1991. Communities in patchy environments: a model of disturbance, competition, and heterogeneity. Pages 97-122 in J. Kolasa and S. T. A. Pickett, editors. Ecological heterogeneity. Springer-Verlag, New York, New York, USA.

Chapin, F. S., III. 1993. Functional role of growth forms in ecosystem and global processes. Pages 287-311 in J. R. Ehleringer and C. B. Field, editors. Scaling physiological processes: leaf to globe. Academic Press, San Diego, California, USA.

Chapin, F. S., III, B. H. Walker, R. J. Hobbs, D. U. Hooper, J. H. Lawton, O. E. Sala, and D. Tilman. 1997. Biotic control over the functioning of ecosystems. Science 277: 500-504.

Chesson, P. L. 1986. Environmental variation and the coexistence of species. Pages 240-256 in T. Case and J. Diamond, editors. Community ecology. Harper and Row, New York, New York, USA.

Collins, S. L. 1989. Experimental analysis of patch dynamics and community heterogeneity in tallgrass prairie. Vegetatio 85:57-66.

Collins, S. L., and S. C. Barber. 1985. Effects of disturbance on diversity in mixed-grass prairie. Vegetatio 64:87-94.

Cook, S. A. 1965. Population regulation of Eschscholzia californica by competition and edaphic conditions. Journal of Ecology 53:759-769.

Craine, J. M., J. Froehle, D. G. Tilman, D. A. Wedin, and F. S. Chapin III. 2001. The relationships among root and leaf traits of 76 grassland species and relative abundance along fertility and disturbance gradients. Oikos 93:274-285.

Crawley, M. J., and M. Nachapong. 1985. The establishment of seedlings from primary and regrowth seeds of a ragwort (Senecio jacobaea). Journal of Ecology 73:255-261.

Denslow, J. S. 1985. Disturbance-mediated coexistence of species. Pages 307-323 in S. T. A. Pickett and P. S. White, editors. The ecology of natural disturbance and patch dynamics. Academic Press, New York, New York, USA.

Desmarais, K. H., and A. J. Tessier. 1999. Performance tradeoff across a natural resource gradient. Oecologia 120:137146.

Díaz, S., and M. Cabido. 2001. Vive la différence: plant functional diversity matters to ecosystem processes. Trends in Ecology and Evolution 16:646-655.

Elberse, W. T., and F. Berendse. 1993. A comparative study of the growth and morphology of eight grass species from habitats with different nutrients availabilities. Functional Ecology 7:223-229.

Fenner, M. 1978. A comparison of the abilities of colonizers and closed-turf species to establish from seed in artificial swards. Journal of Ecology 66:953-963.

Fenner, M. 1985. Seed ecology. Chapman and Hall, New York, New York, USA.

Gaudet, C. L., and P. A. Keddy. 1995. Competitive performance and species distribution in shoreline plant communities: a comparative approach. Ecology 76:280-291.
Gibson, D. J. 1989. Effects of animal disturbance on tallgrass prairie vegetation. American Midland Naturalist 121:144154.

Givnish, T. J. 1987. Comparative studies of leaf form: assessing the relative roles of selective pressures and phylogenetic constraints. New Phytologist 106:131-160.

Gleeson, S. K., and D. Tilman. 1990. Allocation and the transient dynamics of succession on poor soils. Ecology 71:1144-1155.

Goldberg, D. E. 1990. Components of resource competition in plant communities. Pages 357-364 in J. Grace and D. Tilman, editors. Perspectives on plant competition. Academic Press, San Diego, California, USA.

Goldberg, D. E. 1996. Competitive ability: definitions, contingency and correlated traits. Philosophical Transactions of the Royal Society of London B 351:1377-1385.

Goldberg, D., and A. Barton. 1992. Patterns and consequences of interspecific competition in natural communities: a review of field experiments with plants. American Naturalist 139:771-801.

Goldberg, D., and P. A. Werner. 1983. Equivalence of competitors in plant communities: a null hypothesis and a field experimental approach. American Journal of Botany 70: 1098-1104.

Grime, J. P. 1977. Evidence for the existence of three primary strategies in plants and its relevance to ecological theory. American Naturalist 111:1169-1194.

Grime, J. P. 1979. Plant strategies and vegetation processes. John Wiley and Sons, New York, New York, USA.

Grime, J. P. 2001. Plant strategies, vegetation processes, and ecosystem properties. John Wiley and Sons, New York, New York, USA.

Grime, J. P., J. G. Hodgson, and R. Hunt. 1988. Comparative plant ecology: a functional approach to common British species. Unwin Hyman, London, UK.

Grime, J. P., and R. Hunt. 1975. Relative growth rate: its range and adaptive significance in a local flora. Journal of Ecology 63:393-422.

Grime, J. P., et al. 1997. Integrated screening validates primary axes of specialisation in plants. Oikos 79:259-281.

Gross, K. L. 1984. Effects of seed and growth form on seedling establishment of six monocarpic perennial plants. Journal of Ecology 72:369-388.

Gross, K. L., and P. A. Werner. 1982. Colonizing abilities of "Biennial" plant species in relation to ground cover: implications for their distributions in a successional sere. Ecology 63:921-931.

Grubb, P. J. 1985. Plant populations and vegetation in relation to habitat, disturbance and competition: problems of generalization. Pages 595-621 in J. White, editor. The population structure of vegetation. Dr. W. Junk, Dordrecht, The Netherlands.

Grubb, P. J. 1998. Seed mass and light-demand: the need to control for soil-type and plant stature. New Phytologist 138: $169-170$.

Hanski, I. 1983. Coexistence of competitors in patchy environment. Ecology 64:493-500.

Harper, J. L. 1977. Population biology of plants. Academic Press, London, UK.

Harper, J. L., P. H. Lovell, and K. G. Moore. 1970. The shapes and sizes of seeds. Annual Review of Ecology and Systematics 1:327-356.

Hill, M. O., D. F. Evans, and S. A. Bell. 1992. Long-term effects of excluding sheep from hill pastures in North Wales. Journal of Ecology 80:1-13.

Hobbs, R. J., and V. J. Hobbs. 1987. Gophers and grassland: a model of vegetation response to patchy soil disturbance. Vegetatio 69:141-146. 
Howard, T. G., and D. E. Goldberg. 2001. Competitive response hierarchies for germination, growth, and survival and their influence on abundance. Ecology 82:979-990.

Huston, M. 1979. A general hypothesis of species diversity. American Naturalist 113:81-101.

Huston, M., and T. Smith. 1987. Plant succession: life history and competition. American Naturalist 130:168-198.

Jones, C. G., and J. H. Lawton. 1995. Linking species and ecosystems. Chapman and Hall, New York, New York, USA.

Jurado, E., and M. Westoby. 1992. Seedling growth in relation to seed size among species of arid Australia. Journal of Ecology 80:407-416.

Lavorel, S., and P. Chesson. 1995. How species with different regeneration niches coexist in patchy habitats with local disturbances. Oikos 74:103-114.

Lavorel, S., and E. Garnier. 2002. Predicting changes in community composition and ecosystem functioning from plant traits-revisiting the Holy Grail. Functional Ecology 16, in press.

Lavorel, S., S. McIntyre, J. Landsberg, and T. D. A. Forbes. 1997. Plant functional classifications: from general groupings to species groups based on response to disturbance. Trends in Ecology and Evolution 12:474-478.

Leibold, M. A. 1996. A graphical model of keystone predators in food webs: trophic regulation of abundance, incidence, and diversity patterns in communities. American Naturalist 147:784-812.

Levins, R., and D. Culver. 1971. Regional coexistence of species and competition between rare species. Proceedings of the National Academy of Sciences (USA) 68:12461248 .

MacArthur, R. H., and E. D. Wilson. 1967. The theory of island biogeography. Princeton University Press, Princeton, New Jersey, USA.

MacGillivray, C. W., et al. 1995. Testing predictions of the resistence and resilience of vegetation subjected to extreme environments. Functional Ecology 9:640-649.

McIntyre, S., and S. Lavorel. 2001. Livestock grazing in subtropical pastures: steps in the analysis of attribute response and plant functional types. Journal of Ecology 89: 209-226.

McIntyre, S., S. Lavorel, and R. M. Tremont. 1995. Plant life-history attributes: their relationship to disturbances responses in herbaceous vegetation. Journal of Ecology 83 : 31-44.

McPeek, M. A. 1996. Tradeoffs, food web structure, ad the coexistence of habitat specialists and generalists. American Naturalist 148:S124-S138.

Mooney, H. A. 1972. The carbon balance of plants. Annual Review of Ecology and Systematics 3:315-346.

Partridge, L., and P. H. Harvey. 1988. The ecological context of life history evolution. Science 241:1449-1454.

Pianka, E. R. On $r$ - and $K$ - selection. American Naturalist 104:592-597.

Platt, W. J. 1975. The colonization and formation of equilibrium plant species associations on badger disturbances in a tall-grass prairie. Ecological Monographs 45:285-305.

Poorter, H. 1994. Construction costs and payback time of biomass: a whole plant perspective. Pages 111-127 in J. Roy and E. Garnier, editors. A whole-plant perspective on carbon-nitrogen interactions. SPB Publishing, The Hague, The Netherlands.

Poorter, H., and C. Remkes. 1990. Leaf area ratio and net assimilation rate of 24 wild species differing in relative growth rates. Oecologia 83:553-559.
Reader, R. 1998. Relationship between species relative abundance and plant traits for an infertile habitat. Plant Ecology 134:43-51.

Rees, M., R. Condit, M. Crawley, S. Pacala, and D. Tilman. 2001. Long-term studies of vegetation dynamics. Science 293:650-655.

Reich, P. B. 1993. Reconciling apparent discrepancies among studies relating life span, structure and function of leaves in contrasting plant life forms and climates: 'the blind men and the elephant retold.' Functional Ecology 7:721-725.

Sharitz, R. R., and J. F. McCormick. 1973. Population dynamics of two competing annual plant species. Ecology 54: 723-740.

Shipley, B., and R. H. Peters. 1990. The allometry of seed weight and seedling relative growth rate. Functional Ecology 4:523-529.

Southwood, T. R. E. 1988. Tactics, strategies, and templates. Oikos 52:3-18.

Stearns, S. C. 1992. The evolution of life histories. Oxford University Press, New York, New York, USA.

Suding, K. N. 1999. Process responsible for changes in plant species abundance following disturbance. Dissertation. University of Michigan, Ann Arbor, Michigan, USA.

Suding, K. N., and D. E. Goldberg. 2001. Do disturbances alter competitive hierarchies? Mechanisms of change following gap creation. Ecology 82:2133-2149.

Swanborough, P., and M. Westoby. 1996. Seedling relative growth rate and its components in relation to seed size: phylogenetically independent contrasts. Functional Ecology 10:176-184.

Systat. 1991. SYSTAT 5.03 for Windows. Systat, Richmond, California, USA.

Tessier, A. J., M. A. Leibold, and J. Tsao. 2000. A fundamental trade-off in resource exploitation by Daphnia and consequences to plankton communities. Ecology 81:826841.

Thompson, K., et al. 1996. A functional analysis of a limestone grassland community. Journal of Vegetation Science 7:371-380.

Tilman, D. 1988. Plant strategies and the dynamics and structure of plant communities. Monographs in Population Biology 26.

Tilman, D. 1990. Constraints and tradeoffs: toward a predictive theory of competition and succession. Oikos 58:315.

Tilman, D. 1994. Competition and biodiversity in spatially structured habitats. Ecology 75:2-16.

Tilman, D. 1997. Community invasibility, recruitment limitation, and grassland biodiversity. Ecology 78:81-92.

Tilman, D., and D. Wedin. 1991a. Plant traits and resource reduction for five grasses growing on a nitrogen gradient. Ecology 72:685-700.

Tilman, D., and D. Wedin. 1991b. Dynamics of nitrogen competition between successional grasses. Ecology 72:10381049.

Umbanhowar, C. E. 1992. Early patterns of revegetation on artificial earthen mounds in a northern mixed prairie. $\mathrm{Ca}$ nadian Journal of Botany 70:145-150.

Vendramini, F., S. Diaz, D. E. Gurvich, P. J. Wilson, K. Thompson, and J. G. Hodgson. 2002. Leaf traits as indicators of resource-use strategy in floras with succulent species. New Phytologist 154:147-157.

Vincent, T. L. S., D. Scheel, J. S. Brown, and T. L. Vincent. 1996. Trade-offs and coexistence in consumer-resource models: it all depends on what and where you eat. American Naturalist 148: 1038-1058.

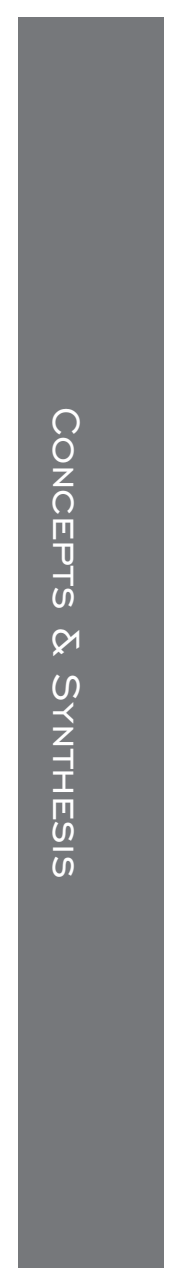


Voss, E. G. 1972, 1985, 1996. Michigan Flora Parts I-III. Cranbrook Institute of Science, Ann Arbor, Michigan, USA. Weiher, E., A. Van der Werf, K. Thompson, M. Roderick, E. Garnier, and O. Eriksson. 1999. Challenging Theophrastus: a common core list of plant traits for functional ecology. Journal of Vegetation Science 10:609-620.
Westoby, M. 1998. A leaf-height-seed (LHS) plant ecology strategy scheme. Plant and Soil 199:213-227.

Westoby, M., M. Leishman, and J. Lord. 1996. Comparative ecology of seed size and dispersal. Philosophical Transactions of the Royal Society of London B 351: 1309-1318. 